\title{
CONTEXTO E PERSPECTIVAS DA FORMAÇÃO DO AGENTE COMUNITÁRIO DE SAÚDE
}

\author{
CONTEXT AND PERSPECTIVES IN THE TRAINING \\ OF THE COMMUNITY HEALTH AGENT
}

Cláudia M. Silva Marques 1

Estela Maura Padilha 2

Resumo $\mathrm{O}$ artigo apresenta algumas reflexões acerca do processo de regulação da formação do agente comunitário de saúde. Faz um breve histórico da criação da ocupação à profissionalização do agente comunitário de saúde, das mudanças exigidas nas formas de organizar os processos de produção de serviços e de formação dos trabalhadores do setor saúde. Apresenta, a seguir, as ações desenvolvidas pelo Ministério da Saúde na construção de instrumentos que subsidiem as instituições formadoras na elaboração dos programas de profissionalização dos agentes comunitários de saúde. Por fim, explicita algumas questões colocadas para os atores incumbidos do desafio de propor a formação profissional para além da atualmente definida.

Palavras-chave formação profissional; escolarização; agente comunitário de saúde; políticas de Abstract The article presents some reflections about the process to regulate the training of community health agents. It briefly describes the trajectory of the occupation, from its creation to its professionalization, as well as the changes required in the organization of the service production processes and of the health workers' training. Next, it deals with the actions developed by the Ministry of Health in order to build instruments to help the training institutions to prepare programmes for the professionalization of the community health agents. Finally, it clarifies some questions raised by those actors that are responsible for proposing forms of professional training that go beyond the current ones. Key words professional training; schooling; community health agent; health policies. 


\section{O Agente Comunitário de Saúde: breve contextualização histórica}

A partir da década de 70, no Brasil, vários programas foram criados, objetivando estender a atenção básica de saúde às populações de difícil acesso aos serviços. Dentre essas iniciativas, o Programa de Interiorização das Ações e Saneamento (Piass) e o Programa de Preparação Estratégica do Pessoal de Saúde (Preps) merecem destaque porque enfatizavam a capacitação de agentes comunitários de saúde.

A Constituição Federal de 1988, ao garantir a universalização do acesso, intensificou a demanda aos serviços de saúde, tradicionalmente centrados no eixo hospitalar. Buscando criar estratégias para reverter este modelo e atender à demanda crescente, várias experiências, em nível local, começaram a surgir, priorizando ações de promoção da saúde e prevenção de agravos, incorporando, em muitas delas, as contribuições da própria população, por meio de sua cultura no 'saber-fazer' os cuidados com sua própria saúde. Estas experiências, sobretudo a do Programa de Agentes Comunitários do Estado do Ceará — implantado em 1988, por iniciativa estadual —, influenciaram a concepção do Programa de Agentes Comunitários de Saúde (Pacs), institucionalizado pelo Ministério da Saúde/Fundação Nacional de Saúde, em 1991.

O Pacs foi pensado como uma estratégia de transição para outra mais abrangente - o Programa de Saúde da Família (PSF) —, que teve sua implantação em 1994. Estas duas estratégias constituíram-se caminhos possíveis no processo de reorganização da atenção básica em saúde, representando uma intervenção concreta no contexto da mudança do modelo de atenção à saúde. Suas concepções buscam contribuir na redução de graves problemas enfrentados pelos serviços públicos: a ênfase em práticas de combate a doenças instaladas e a falta de vínculo com a população assistida. Com o Pacs/PSF, uma nova dinâmica de atuação nas unidades básicas de saúde passa a ser incorporada: os serviços passam a buscar estratégias para desenvolver uma atenção integral à saúde de indivíduos, grupos e famílias, intervir sobre fatores de risco aos quais a população está exposta, promover parcerias por meio de ações intersetoriais, estimular o controle social e eleger a família e seu espaço social como núcleo básico de abordagem na atenção à saúde.

Por outro lado, desde a implantação do Pacs, os agentes comunitários de saúde vêm se organizando em busca do reconhecimento legal da profissão e, com a expansão do PSF e a conseqüente incorporação destes trabalhadores nas equipes multiprofissionais, houve uma ampliação das aspirações do reconhecimento de sua identidade profissional e de seus direitos trabalhistas e sociais.

A organização dos agentes comunitários de saúde propiciou a edição do Decreto Federal no 3.189/99, que fixa as diretrizes para o exercício de suas atividades e, posteriormente, a elaboração de projeto de lei para a criação 
da profissão, que culminou na publicação da Lei Federal no 10.507, de 10 de julho de 2002, que cria a profissão de agente comunitário de saúde (ACS).

\section{Ser profissional ACS: perspectivas do setor saúde}

A introdução de inovações tecnológicas e de novas formas de organização do trabalho em saúde, onde o planejamento, a promoção, a prevenção de agravos e a atenção integrada buscam garantir acesso e qualidade na prestação dos serviços, exige, do setor saúde, profundas mudanças na forma de organizar os processos de produção dos serviços e de formação dos trabalhadores. Tomando como referência doutrinária a Reforma Sanitária e como estratégia de reordenação setorial e institucional, o Sistema Único de Saúde (SUS), o desenvolvimento das práticas profissionais nos diferentes espaços e contextos onde ocorrem os cuidados à saúde deve incorporar a concepção ampliada de saúde, com foco na qualidade de vida, fazendo emergir conceitos importantes, tais como o trabalho em equipe, a interdisciplinaridade e a intersetorialidade.

Assim, 'fazer saúde' exige profissionais com capacidade de atuar nos diferentes setores, de forma a promover a melhoria dos indicadores de saúde, em qualquer nível de atenção presente no sistema. Isto requer, dentre outras questões, a compreensão global do processo de trabalho, uma maior articulação entre os diversos setores, a recomposição dos trabalhos parcelados. Para o setor saúde, portanto, a formação dos trabalhadores é reconhecida e valorizada como componente deflagrador de um processo de reajuste da força de trabalho, no sentido de contribuir decisivamente para a efetivação da política nacional de saúde.

Esta forma de conceber a formação busca caracterizar a necessidade de elevação da escolaridade dos trabalhadores e, ainda, proporcionar a compreensão global do processo produtivo, com a apreensão do saber tecnológico, a valorização da cultura do trabalho e a mobilização dos valores necessários à tomada de decisões. A profissionalização assim concebida gera uma proposição de elevação dos perfis profissionais dos trabalhadores da saúde, traduzida como aumento de sua autonomia intelectual - domínio do conhecimento técnico-científico, capacidade de autoplanejar-se, de gerenciar seu tempo e espaço de trabalho, de exercitar a criatividade, de trabalhar em equipe, de interagir com os usuários dos serviços, de ter consciência da qualidade e das implicações éticas do seu trabalho.

Promover qualificação profissional mediante processos sistemáticos de formação é estratégia fundamental quando se concebe a educação como instrumentação da cidadania, desde que ela seja promovida de forma "crítica e reconstrutiva, estabelecendo um dos caminhos mais efetivos para a emer- 
gência do sujeito histórico capaz de projeto próprio coletivo, tal como é requerido pela construção do SUS" (Demo, 1997, p. 9).

O profissional agente comunitário de saúde atua no apoio aos indivíduos e coletivos sociais, realizando atividades de promoção da saúde e prevenção de agravos, por meio de ações educativas e de acompanhamento a indivíduos, famílias e grupos, mobilizando práticas de promoção da vida em coletividade e de desenvolvimento de interações sociais. Estas características apontam para uma singularidade e especificidade profissional, que o situa na interface intersetorial da saúde, ação social, educação e meio ambiente. Para o setor saúde, a formação do agente comunitário requer, então, a identificação técnica, ética e humanística das competências que ele deve desenvolver para a realização de seu trabalho.

A análise da Portaria GM/MS no 1.886/97, que estabelece as atribuições do agente comunitário de saúde, e do Decreto Federal no 3.189/99, que fixa diretrizes para o exercício de suas atividades, possibilitou uma proposição qualitativa de suas ações, evidenciando os eixos estruturantes de sua prática. Esta análise e a necessidade de preparar profissionais adequados às políticas e estratégias desenvolvidas pelo SUS, bem como às concepções de formação assumidas pelo setor, sinalizaram para o Ministério da Saúde a importância da construção de instrumentos que possam subsidiar as instituições formadoras na elaboração dos programas de profissionalização dos agentes comunitários de saúde.

\section{O caminho da formação: relato das ações desenvolvidas}

O Ministério da Saúde, buscando alternativas que possibilitem maior ajustamento entre os desenhos de organização da atenção à saúde propostos nacionalmente e a construção de programas de ensino, incorporou um conceito de competência profissional que remete necessariamente à vinculação educação-trabalho:

“capacidade de enfrentar - com iniciativa e responsabilidade, guiados por uma inteligência prática do que está ocorrendo e com capacidade para coordenar-se com outros atores para mobilizar suas capacidades - situações e acontecimentos próprios de um campo profissional" (Zarifian, 1999, p. 33).

Este conceito traduz uma visão do trabalho como conjunto de acontecimentos, com forte dose de imprevisibilidade e baixa margem de prescrição, contrariamente ao que propõem os estudos clássicos sobre a organização e gestão do trabalho, identificados como fordismo, taylorismo ou fayolismo. Esta visão do trabalho é especialmente importante para o setor saúde, onde 
as decisões a serem tomadas implicam a articulação de vários saberes, e o processo de produção dos serviços não admite rotinas rígidas, sendo, ao contrário, necessária uma constante ressignificação destas rotinas. Além disto, tal acepção implica a reconceitualização da formação profissional, que deixa de ser a disponibilidade de um "estoque de saberes" para se transformar em "capacidade de ação diante de acontecimentos" (Zarifian, 1999, p. 33).

Para a saúde, considerar competência nestes termos possibilita ao trabalhador conhecer a utilidade e os impactos das ações que realiza, compreender que os grupos sociais não são abstratos ou distantes, conhecendo suas necessidades e modos de viver e, sobretudo, compreender a importância do processo de interação da equipe de trabalho com os indivíduos, grupos e coletividades com os quais trabalha.

A partir dessas definições, foi desenvolvida a proposta de perfil de competências profissionais do agente comunitário de saúde, cuja elaboração obedeceu a cuidados exaustivos, associando grupos de especialistas e trabalhadores, oficinas de trabalho e seminários. As competências profissionais do agente comunitário expressam as dimensões do trabalho deste profissional, e cada competência representa um eixo estruturante de sua prática. Optou-se, na redação da competência, por uma formulação abrangente e generalizável, coerente com a nova perspectiva de organização dos processos de formação e trabalho, claramente identificados com o trabalho de equipe.

Além disso, partiu-se do pressuposto de que a competência profissional incorpora três dimensões do saber: o saber-conhecer, o saber-ser e o saberfazer. Estas dimensões da competência profissional estão expressas nas habilidades (saber-fazer), nos conhecimentos (saber-conhecer) e nas atitudes (saber-ser).

Considerando a complexidade e a relevância do assunto, a proposta de perfil de competências profissionais do agente comunitário de saúde foi submetida à consulta pública, permanecendo na página eletrônica do $\mathrm{Mi}$ nistério da Saúde no período de 31 de outubro a 31 de dezembro de 2003. Esta consulta representou um importante passo do Ministério, por meio da Secretaria de Gestão do Trabalho e da Educação na Saúde, para a ampliação do debate em torno das políticas públicas para a formação e educação permanente dos trabalhadores do setor. O número de acessos registrados no endereço da consulta (4.930, com 698 pessoas/instituições cadastradas e 385 opiniões registradas no formulário de sugestões) demonstrou o interesse e a relevância dada ao assunto, reforçando a necessidade de, cada vez mais, democratizar o acesso e garantir espaços de participação dos vários atores e segmentos sociais às proposições relativas às políticas para ordenação da formação na área da saúde.

A pertinência dos questionamentos, críticas e sugestões recebidas demandaram importantes reflexões ao documento apresentado, gerando revi- 
sões de forma e de conteúdo, de modo a incorporar, se não totalmente, pelo menos grande parte das contribuições recebidas. A partir destas sugestões, percebeu-se a necessidade de, não apenas alterar redações, mas de melhor adequar habilidades e conhecimentos aos eixos da prática profissional do agente comunitário de saúde expressos em cada competência.

Desta forma, estão propostas as seguintes competências profissionais para o agente comunitário (MEC, MS, 2004):

- Desenvolver ações que busquem a integração entre as equipes de saúde e a população adscrita à unidade básica de saúde, considerando as características e as finalidades do trabalho de acompanhamento de indivíduos e grupos sociais ou coletividades;

- Realizar, em conjunto com a equipe, atividades de planejamento e avaliação das ações de saúde no âmbito de adscrição da unidade básica de saúde; - Desenvolver, em equipe, ações de promoção da saúde visando a melhoria da qualidade de vida da população, a gestão social das políticas públicas de saúde e o exercício do controle da sociedade sobre o setor da saúde;

- Desenvolver ações de prevenção e monitoramento dirigidas às situações de risco ambiental e sanitário para a população, conforme plano de ação da equipe de saúde;

- Desenvolver ações de prevenção e monitoramento dirigidas a grupos específicos e a doenças prevalentes, conforme definido no plano de ação da equipe de saúde e nos protocolos de saúde pública.

O documento final do perfil de competências profissionais do agente comunitário de saúde deverá ser resultante de um acordo ou consenso entre os atores sociais envolvidos com o trabalho deste profissional e, como se trata de uma negociação, o limite de eventuais transigências ficará por conta das deliberações da política do Ministério da Saúde.

\section{Desafios do caminho: buscando alternativas para a formação do ACS}

O contexto sócio-político em que se insere esta nova categoria profissional e as peculiaridades da Lei no 10.507, que cria a profissão Agente Comunitário da Saúde, trazem importantes questões ainda não resolvidas para este debate.

Nos termos da Lei 10.507, “o exercício da profissão de Agente Comunitário de Saúde dar-se-á exclusivamente no âmbito do Sistema Único de Saúde". Apresentam-se ainda, no Artigo 3o, os seguintes requisitos para o exercício da profissão: "residir na área da comunidade em que atuar; haver concluído com aproveitamento curso de qualificação básica para a formação de Agente Comunitário de Saúde; haver concluído o ensino fundamental".

Estas definições trazem implicações jurídico-legais tanto para a regulação do trabalho quanto para a formação dos agentes comunitários e levanta 
questões importantes em relação às perspectivas delineadas, pelo Ministério da Saúde, para a educação profissional, que uma concepção de formação que possibilite ao trabalhador uma elevação de sua escolaridade e de seu perfil de desempenho profissional. Somam-se a isto, os dados obtidos pelo Ministério da Saúde acerca da escolaridade desses trabalhadores, que revelam um perfil em que aproximadamente $60 \%$ possuem ensino médio completo ou incompleto; $18 \%$, o ensino fundamental completo e $22 \%$ estão por concluir o ensino fundamental (MS, 2003b).

Neste sentido, as definições da política da educação profissional para o setor saúde, a importância do agente comunitário no contexto de mudanças das práticas de saúde e seu perfil de escolaridade apontam para uma proposição de formação profissional para além daquela atualmente definida. $\mathrm{O}$ debate está, em certa medida, apenas começando e, dada à complexidade do assunto, o percurso certamente será revelado durante o caminhar dos vários atores incumbidos deste desafio.

\section{Notas}

1 Consultora Técnica do Departamento de Gestão da Educação na Saúde, da Secretaria de Gestão do Trabalho e da Educação na Saúde, do Ministério da Saúde. Especialista em Desenvolvimento de Recursos Humanos para o Sistema Único de Saúde (UnB/OPS). <clamarquesilva@uol.com.br>

2 Consultora Técnica do Departamento de Gestão da Educação na Saúde/Secretaria de Gestão do Trabalho e da Educação na Saúde/Ministério da Saúde. Especialista em Gestão de Recursos Humanos para o Sistema Único de Saúde (UnB). <estela.padilha@saude.gov.br> 


\section{Referências}

BRASIL. 2002. Lei n. 10.507, de 10 de julho de 2002. Cria a profissão de agente comunitário de saúde e dá outras providências. Diário Oficial da União, 2002.

DEMO, Pedro. 1997. Educação profissional: desafio da competência humana para trabalhar. In: Educação profissional: o debate da(s) competência(s). Brasília: $\mathrm{MTb} / \mathrm{SEFOR}$, p. 7-22.

MARQUES, Cláudia M. Silva. 2002. As necessidades do Sistema Único de Saúde e a formação profissional baseada no modelo de competências. Revista Formação, v. 2, n. 5., p. 17-27.

MARQUES, Cláudia M. Silva. 2003. Sistema de certificação de competências/Profae: contextualização, implementação e perspectivas. Brasília: Ministério da Saúde. (Mimeo).

MEC (Ministério da Educação); MS (Ministério da Saúde). 2004. Referencial curricular para curso técnico de agente comunitário de saúde. Brasília: Editora MS.

MS (MINISTÉRIO DA SAÚDE). 1999a. Coordenação Geral de Desenvolvimento de Recursos Humanos para o SUS/SPS. Coordenação de Atenção Básica/SAS. Diretrizes para elaboração de programas de qualificação e requalificação dos agentes comunitários de saúde. Brasília. Mimeo. 1999b. Proposta de diretrizes curriculares nacionais para o ensino técnico na área de saúde. Brasília. (Texto elaborado pela equipe constituída pelo Ministério da Educação e Ministério da Saúde, com apoio técnico da OPS). Mimeo.

2000. Referências conceituais para a organização do sistema de certificação de competências/Profae. Brasília. (Mimeo). . 2003a. Politica de educação profissional: versão preliminar. Brasília. (Mimeo). 2003b. Siab/Sistema de Informação da Atenção Básica. (Mimeo).

2004a. Perfil de competências profissionais do agente comunitário de saúde: versão preliminar. Brasília. (Mimeo).

2004b. Consulta pública da minuta de perfil de competencias profissionais do agente comunitário de saúde: relatório preliminar. Brasília. (Mimeo).

ZARIFIAN, Philippe. 1990. Organization qualificante et capacité de prise de décision dans $l^{\prime}$ industrie. (Mimeo).

1998. A gestão da e pela competência. In: Seminário Internacional Educação Profissional, Trabalho e Competências, Rio de Janeiro. Anais. Rio de Janeiro: Senai/ DN-CIET.

1999. Objective compétence. Paris: Liason. 